Essay

\title{
The Impact of Soil and Water Conservation on Agricultural Economic Growth and Rural Poverty Reduction in China
}

\author{
Abdul Samad Abdul-Rahim ${ }^{1, *}$, Chenglong Sun ${ }^{1,2}$ and A. W. Noraida ${ }^{1}$ \\ 1 Faculty of Economics and Management, Universiti Putra Malaysia, Serdang 43400, Malaysia; \\ sunscl@msn.cn (C.S.); aidawahob@gmail.com (A.W.N.) \\ 2 Center of Environmental Justice Research, School of Law, Nankai University, Tianjin 300350, China \\ * Correspondence: abdrahim_as@upm.edu.my; Tel.: +60-3-89467654
}

Received: 23 August 2018; Accepted: 6 October 2018; Published: 27 November 2018

\begin{abstract}
There is a lack of systematic study on the impact of soil and water conservation on the sustainable development of agricultural economies and rural poverty reduction in China. This study investigates the effects of soil and water conservation on agricultural economic growth. It looks at levels of disposable income in rural households in China and uses the econometric method to examine panel data obtained from 30 provinces between 2003-2012. Agricultural gross domestic product (GDP) is the dependent variable, and soil and water conservation are the independent variables. Farmland area, along with four other variables, is the control variables that are used to establish the Cobb-Douglas production function and provide further data. It was found that soil and water conservation have a significant impact on the per capita income of rural households in China. The findings support that soil and water conservation can contribute to the agricultural economic growth and rural poverty reduction in China. There is evidence that supports the idea that soil quality and capital input are now more important in poverty reduction and economic growth than farmland area and agricultural labour. The government and farmers need to prioritise investment in soil and water conservation in order to promote the development of agricultural economies and reduce rural poverty.
\end{abstract}

Keywords: soil and water conservation; agricultural economic growth; rural poverty reduction; China

\section{Introduction}

In the past 30 years, the degradation of land resources in China has worsened due to population growth and the rapid expansion of the rural economy. China also has a significant problem with soil erosion [1]. According to the third national soil erosion survey, from 1997 to 2003, affected areas increased by $14 \%$ [2]. The total annual soil loss reached approximately five billion tons. The size of the soil erosion areas, erosion intensity, and the danger posed shows a worrying trend in some areas (Figure 1). 


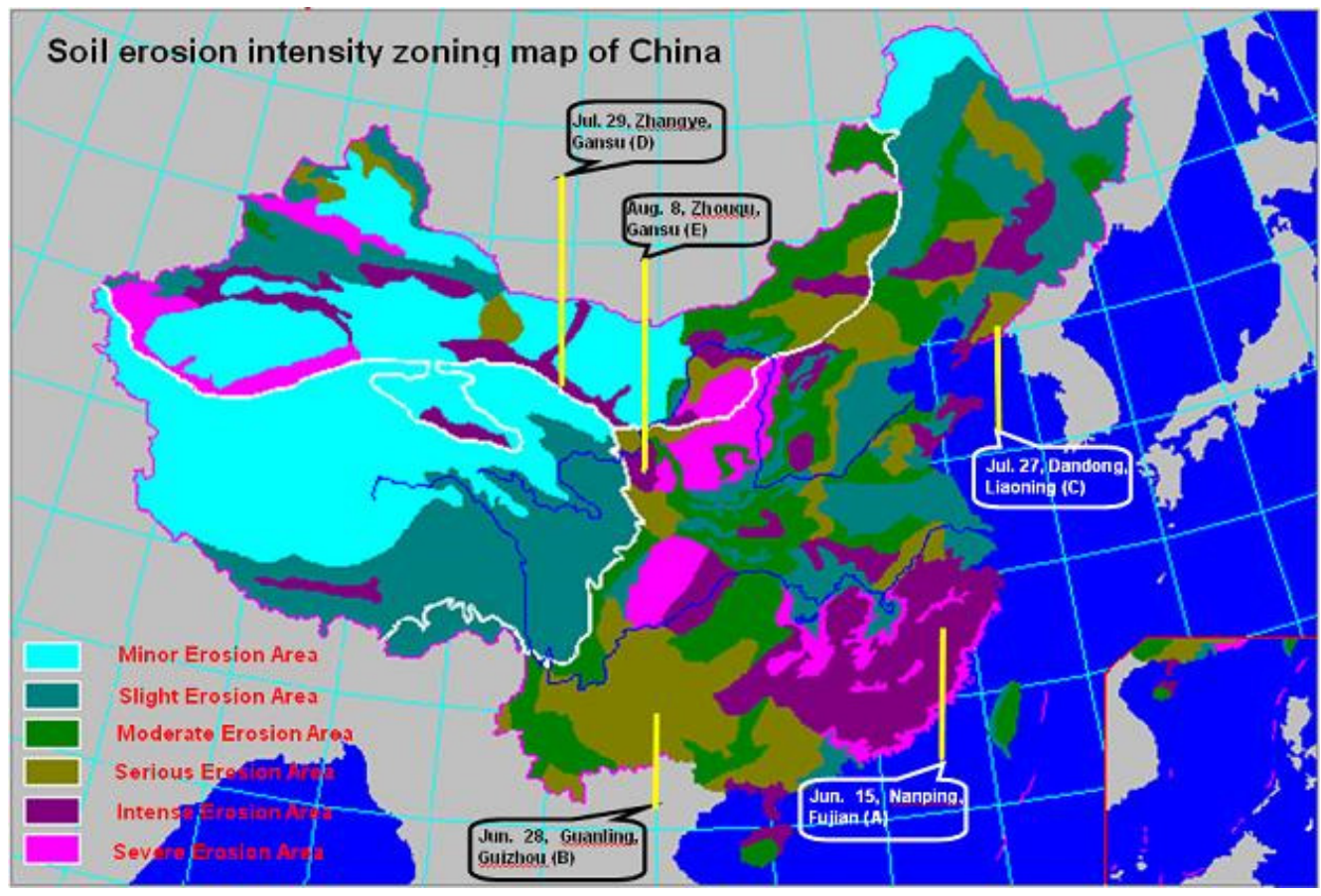

Figure 1. Soil Erosion Intensity Zoning map of China [3].

So much so that the Chinese government has made soil and water conservation a priority. Through long-term planning and treatment projects, they are targeting the rural areas that are affected by soil erosion. In 1991, the Chinese people's Congress promulgated "The Law of the People's Republic of China on Soil and Water Conservation". This law means that soil and water conservation in China is controlled and subject to the legal requirements. Soil erosion is managed through a range of agricultural, biological, and engineering techniques [4]. The government recently established management and conservation projects in the upper reaches of the Yangtze and Yellow rivers, sandstorm prevention projects in Beijing and Tianjin, water resources management in Beijing, and slit arresting on the Loess Plateau, the Beipanjiang River, and the Zhujiang River [5]. The government provides guidelines and establishes practices for soil and water conservation. However, in many areas, they have not captured the enthusiasm of the farmers. The national watershed management approach may be more a more effective way of doing this, not only within a project area but also in the broader area.

Meanwhile, the statistics indicate that China agricultural sector is one of the most vital components of the economy, occupying more than $12 \%$ of the total gross domestic product (GDP) (Refer Figure 2). Over 300 million people in China work in the agriculture sector, accounting for nearly 50\% of China's whole workforce. The statistics also prove that it supplies the most significant output compared to other countries over the world. However, only $15 \%$ of the total land available in China can be cultivated [6], which is divided by nearly 200 million households, with less than two acres of land per capita. The shortage of cultivated land has sometimes aroused problems in China's long history (Refer to Figure 3). 


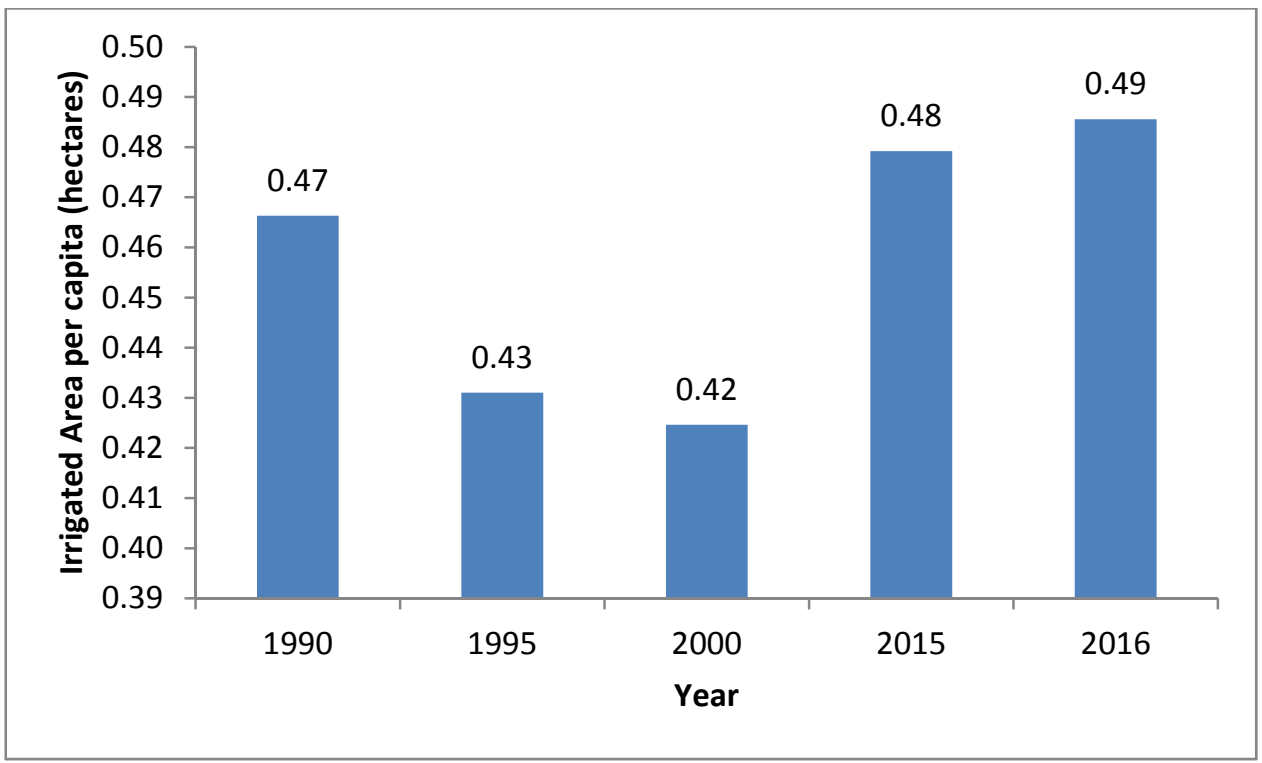

Figure 2. Irrigated Area per Capital, (1990-2016) [7].

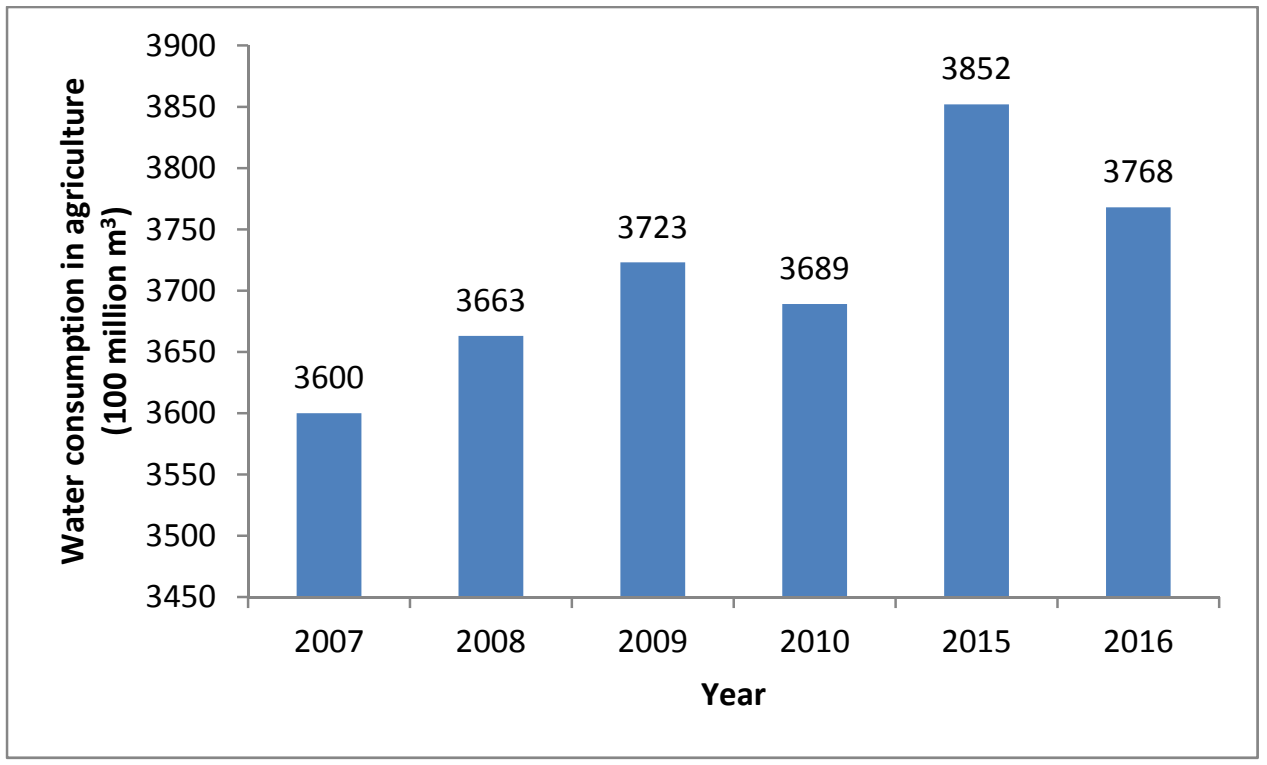

Figure 3. Water Consumption in the Agriculture Sector [7].

In China, most of the low-income people live in the countryside, and the same economic growth seen in other sectors of the economy has been absent in rural communities. China's farms are relatively small in size compared to farms in other countries and are on average one acre in size. Due to the nature of agriculture and sometimes outdated farming practices, the work is highly labour-intensive. However, the majority of farmers still lives in poverty and earn an average of $\$ 1000$ annually. This figure is less than one-third of the average income in urban areas [7]. In China's case, poverty reduction is closely related to the income inequality created by the rapid growth of urban areas over the last 20 years [8].

Raising farmers' income is one of the urgent policy challenges faced by China's government right now. In this way, a comprehensive model of soil and water conservation system that adapts to China's socio-economic situation has developed. This is because soil and water conservation practices are closely related to the economic, social, and natural development. Management practices and operation styles of the soil and water conservation are worth being reviewed and improved.

Identifying how to increase income levels in rural areas is an urgent challenge that is currently facing the Chinese government. In light of this, a comprehensive soil and water conservation system 
adapted to China's socio-economic situation was developed. Soil and water conservation practices are closely related to economic and social development. The operational and management practices that are related to soil and water conservation are worthy of review and improvement.

Since the reform in 1978, China has made considerable progress in soil and water conservation, agricultural economic growth, and poverty reduction. The area of soil and water conservation is regarded by many as a basis to evaluate environmental conditions in China. Soil and water projects have accelerated the development of the agricultural economy; this is evident from the continuous increase seen in GDP in rural areas [7].

The impact of soil, water quality, and fertilisers on human health are widely debated. According to [9], the nature of the soil can have positive and negative effects on humans. A chemical imbalance and the presence of human pathogens in the soil biology can have negative health impacts. In certain places, toxic elements or chemicals are present in the soil as a result of the natural or anthropogenic activity. The soil in urban environments is the subject of increased focus and has raised many questions related to the impact of soil contamination on human health.

China is one of the largest producers and consumers of lead and zinc in the world. These elements and others such as cadmium are deposited into the environment during mineral processing, causing significant damage to local water resources. Water conservation is very important to human health, as the efficient supply of drinking water is essential for human survival [10].

In addition, traditional agricultural fertilisers lead to elevated heavy metal concentrations that are found in parts of China [11-13]. Vegetables absorb heavy metals from contaminated soil and also from the presence of chemicals in air pollution [14]. The chronic intake of heavy metals has damaging effects on humans and wildlife $[15,16]$.

The study of soil and water conservation on agricultural economic growth and rural poverty reduction in China is crucial because of the large soil erosion problems that it faces. This study investigates the factors affecting agricultural economic growth and rural poverty reduction in China.

\section{Literature Review}

Many articles promote the importance of land as a type of capital in agriculture economic growth and poverty reduction [17]. Reardon and Vosti [18] stated that the link between environmental degradation and poverty depends on the level of poverty. Soil erosion is one of the most significant problems related to rural and agricultural economic growth [19]. It results in land degradation, hinders cultivation, and reduces productivity and land capacity. The research by [20] showed that poverty could not be caused solely by soil contamination if the water supply is clean. However, it can be caused if both the water and soil are contaminated. Several studies are available that investigate the economic impacts of soil and water conservation in China.

Xiaoman et al. [21] found that the counties with severe soil and water loss are likely to have high levels of state and personal poverty, indicating a close link. Further studies show that poverty is not a prime cause of soil and water loss, but water and soil loss was identified as a principal cause of poverty in some areas. It is unlikely that soil and water conservation will fully eradicate poverty, but conservation work should focus on the alleviation of poverty through projects related to water and soil.

Baofeng et al. [22] applied statistical analysis to prove that there is a geographical link between poverty and the distribution of water and soil loss. They are dependent on each other as both cause and effect. Damage to ecological environments results in water and soil loss, limiting the efficient use of resources, and adding environmental pressures. The root of ecological deterioration and poverty is water and soil loss. Therefore, the promotion of soil and water conservation offers many benefits, and in some areas, the sustainable use of water and soil has been achieved. These types of projects improve the local environment, increase rural incomes, and alleviate poverty.

Shiming [23] conducted a study investigating the link between water and soil loss and poverty. It used the synthetic panel data of soil erosion incidence and poverty incidence. It discovered that the 
incidence of soil erosion is correlated with poverty. Additionally, there are regional differences in their dynamic changes, mapping the economic development level of different regions.

Yuanpei and Hehua [24] analyzed the contribution of soil and water conservation to the development of the agricultural economy and poverty alleviation in China by using the econometric method. The results show that soil and water area conservation and the loss of soil and water has no significant impact on China's rural GDP. However, it may promote the long-term growth of the agricultural economy in China to a certain extent. Soil and water conservation has a significant impact on average incomes in rural areas, which are conducive to alleviating poverty. In contrast, the growth of agricultural GDP shows no direct link to the development of the controlled soil and water loss areas.

Lu and Chen [25] conducted research based on soil erosion data on 1986, 1996, and 2002, and the results showed that soil and water loss had an adverse impact on agricultural economic growth. The area with the lowest productivity is western China, and it is the area with the most severe soil erosion. To eliminate soil erosion and rural poverty, agricultural development must be transformed from the extensive to the intensive, thus achieving the goal of environmental protection.

There are many studies on soil erosion and poverty. However, the method of using soil erosion to reduce rural poverty, and soil and water conservation has attracted little attention from Chinese researchers. Few have shown the impacts of soil and water conservation on poverty, food security, or other outcomes of interest [26]. Therefore, further study is essential to detect the relationship between soil and water conservation and rural poverty reduction.

Few previous studies of soil and water conservation have focused on rural areas. Throughout history, Chinese farmers have developed many practical techniques and technologies to conserve soil and water. Current devices and techniques are more advanced and developed. Soil and water conservation are also determined by the private decisions of rural households. Decisions made by rural households on the expansion of farms, the types of crops, investments, and land use all impact conservation efforts. Governmental policies and regulations related to land use also impact conservation efforts. For these reasons, further investigation of the impacts of soil and water conservation on rural poverty is needed.

\section{Model, Methodology, and Data}

The Cobb-Douglas model was adapted from the log-linear form of the classic Cobb-Douglas production function:

$$
P(L, K)=b L^{\alpha} K^{\beta}
$$

where $P$ is the total production, $L$ is the labour input, $K$ is the capital input, $b$ is the total factor productivity, and $\alpha$ and $\beta$ represent the output elasticities of labour and capital, respectively. These values are constants that are determined by the available technology. The Cobb-Douglas model was formulated and tested by Charles Cobb and Paul Douglas from 1927 to 1947. It is the most suitable and applicable model in terms of describing sources of growth.

This study uses the model adapted from [25], who extended the Cobb-Douglas model to suit their study. The independent variable of the soil and water loss area has been changed to the soil and water conservation area. Many believe that a noticeable reduction of poverty in rural China is due to the increase in household incomes over a long period of time [27]. Disposable income per capita is used to measure rural poverty reduction and is added as the second dependent variable. This study focuses on both the macro and micro levels. The proposed model was augmented to include the control variables that are essential to the study. To eliminate the potential heteroscedasticity problem, the translog production function was applied in this study. These models are shown below:

Model 1:

$$
\begin{gathered}
\operatorname{Ln}\left(\mathrm{AGDP}_{i t}\right)=\alpha+\beta_{1} \operatorname{Ln}\left(\mathrm{SWCA}_{i t}\right)+\beta_{2} \operatorname{Ln}\left(\operatorname{LAND}_{i t}\right)+\beta_{3} \operatorname{Ln}\left(\text { LABOR }_{i t}\right)+\beta_{4} \operatorname{Ln}\left(C_{\text {CAPITAL }}\right) \\
+\beta_{5} \operatorname{Ln}\left(\operatorname{IRA} / L A N D_{i t}\right)+\beta_{6} \operatorname{Ln}\left(\text { FER }_{i t}\right)+\varepsilon_{i t}
\end{gathered}
$$


Model 2:

$$
\begin{gathered}
\operatorname{Ln}\left(\mathrm{PIRH}_{i t}\right)=\alpha+\beta_{1} \operatorname{Ln}\left(\mathrm{SWCA}_{i t}\right)+\beta_{2} \operatorname{Ln}\left(L A N D_{i t}\right)+\beta_{3} \operatorname{Ln}\left(\operatorname{LABOR}_{i t}\right)+\beta_{4} \operatorname{Ln}\left(\text { CAPITAL }_{i t}\right) \\
+\beta_{5} \operatorname{Ln}\left(\operatorname{IRA} / L A N D_{i t}\right)+\beta_{6} \operatorname{Ln}\left(\mathrm{FER}_{i t}\right)+\varepsilon_{i t}
\end{gathered}
$$

The social and economic development of the region is heavily determined by the natural geographical environment. However, external social and economic development policies are also influential factors that affect poverty levels. Therefore, the debate around poverty should take all of the factors into account. For the purpose of this study, AGDP represents agricultural GDP, PIRH is the per capita disposable income of rural households, SWCA is the soil and water conservation area, LAND is the farmland area, LABOR is the number of agricultural workers, CAPITAL is the agricultural productive fixed assets, IRA is the irrigation area, FER is the consumption of chemical fertilizer, and $\varepsilon$ is the error term. The letters $i$ and $t$ represent the province and the time-specific data. The disturbance item is that which represents time and individual change. The limitation of the model lies in the lack of dummy variables, which means that the eco-geographical regionalisation is not represented.

\section{Method of Data Analysis}

Eviews 7 was used to examine the impacts on agricultural GDP growth and per capita income of rural households in China by applying the pooled ordinary least squares (OLS), fixed effect, and random effect approach. Due to $\mathrm{N}>\mathrm{T}$, cross-section weights were added.

\subsection{Pooled OLS}

The pooled OLS relies on independently pooled panels. Its fundamental assumption is that there are no unique attributes of individuals within the measurement set, and no universal effects across time. The most straightforward approach to run such data is to estimate a pooled regression that involves estimating a single equation applicable to all of the data.

\subsection{Fixed Effect}

It explores the relationships between all of the dependent variables and independent variables within the model. The independent variables have different characteristics so that they may influence the dependent variables. It is assumed that there is a correlation between independent variables and individual effect. They assist in removing the omitted variable bias by measuring changes in the variables. Some of the advantages include the control of bias among variables to assess the predictors' net effect on outcome variables, and the elimination of the effect of time-invariant characteristics.

\subsection{Random Effect}

In contrast to the fixed-effect model, variation across the dependent variables is thought to be random and not related to the independent variables that are included in the regression. In random effect, specific characteristics that may not affect the dependent variables must be specified. It is assumed that there is no correlation between the independent variables and specific individual effects. Advantages of the random effect are that it generalizes inferences from the sample used in the regression, and includes time-invariant variables.

\subsection{Hausman Test}

The Hausman test was carried out to decide which was the most suitable, between fixed or random effects. The Hausman test hypothesis stated that the random effect model was the preferred option. The random effect tests identified if the different errors $\left(u_{i}\right)$ correlated with the repressors; the null hypothesis showed no correlation. 


\subsection{Data}

The data analysis is based on panel data for all of the indicators from 30 provinces in China. The data was gathered from 2003 to 2012. This period was chosen because of the lack of availability of more recent data. The soil and water conservation area in Shanghai is 0; therefore, Shanghai is not included in the study. Similarly to [25], this study uses data from 30 provinces in China starting from the year 2003 to 2012 and includes a total of 300 observations. The Beijing, Tianjin, Tibet, Chongqing, and Hainan provinces are evaluated independently for the first time. This study uses more current data than [25], who based their study on the years 1986, 1996, and 2002. To ensure that a comprehensive set of results were produced, the samples that were used in the sections and the date ranges were larger than those from previous studies. The data was collected from the National Bureau of Statistics of the People's Republic of China. AGDP stands for Agricultural GDP and is measured by the value of inflow in $10^{9}$ Yuan. PIRH represents the per capita disposable income of rural households and is shown in Chinese Yuan. SWCA stands for soil and water conservation and is measured in units of $103 \mathrm{hm}^{2}$. Other control variables in this study were tested to observe the significance of the two dependent variables, AGDP and PIRH. These include farmland area $\left(10^{6} \mathrm{hm}^{2}\right)$, the number of agricultural laborers $\left(10^{4}\right.$ people), agricultural productive fixed assets $\left(10^{6}\right.$ Yuan), irrigation area $\left(10^{6} \mathrm{hm}^{2}\right)$, and consumption of chemical fertilizer $\left(10^{4} \mathrm{t}\right)$.

\subsection{Description of Variables}

The description of the variable using in this study was explained in Table 1.

Table 1. Description of Variables.

\begin{tabular}{ll}
\hline Variables & Definition \\
\hline AGDP & $\begin{array}{l}\text { The monetary value of all of the finished goods and services produced in a country during } \\
\text { a specified period. It equals a total of private and public spending, government spending, } \\
\text { investments, and net exports, which were calculated as total exports minus imports. }\end{array}$ \\
\hline PIRH & $\begin{array}{l}\text { Disposable income of rural households represented as the total income of rural households } \\
\text { from different kinds of sources minus all of the related expenses. }\end{array}$ \\
\hline SWCA & $\begin{array}{l}\text { Index to measure the soil and water conservation situation in China. Soil and water } \\
\text { conservation area are measured by unit } 10^{3} \mathrm{hm}^{2} .\end{array}$ \\
\hline$L A N D$ & The total area of farmland. \\
\hline LABOR & Total agriculture labour employed. \\
\hline CAPITAL & Total agricultural capital stock. \\
\hline IRA/LAND & Total irrigation area per total area of farmland. \\
\hline
\end{tabular}

\section{Result and Discussion}

\subsection{Empirical Result}

As discussed, the study uses two models to evaluate the impact of soil and water conservation on agricultural GDP and the impact on the per capita disposable income of rural households.

Based on the results of the Hausman test, it is significant at the $1 \%$ level, and we can conclude that the fixed effect model is preferable (Refer to Table 2). The soil and water conservation, agriculture capital stock, irrigation area per total area of farmland, and consumption of chemical fertilizer had positive impacts on the agricultural production output. However, the area of farmland and the number of people employed in the agriculture sector both had negative impacts on the agricultural production output. 
Table 2. The Impact of Soil and Water Conservation on Agricultural Gross Domestic Product.

\begin{tabular}{cccc}
\hline IV & Pooled OLS & Fixed Effect & Random Effect \\
\hline \multirow{2}{*}{ Constant } & $-2.9227^{* * *}$ & $6.8523^{* * *}$ & $5.5277^{* * *}$ \\
& $(-9.8997)$ & $(5.8889)$ & $(-13.2266)$ \\
\hline \multirow{2}{*}{ LnSWCA } & 0.0242 & $0.1182^{* * *}$ & $0.1326^{* * *}$ \\
& $(1.4688)$ & $(4.1779)$ & $(5.5656)$ \\
\hline \multirow{2}{*}{ LnLAND } & $0.1809^{* * *}$ & $-0.5135^{* * *}$ & 0.0404 \\
& $(4.2631)$ & $(-3.9468)$ & $(0.5611)$ \\
\hline \multirow{2}{*}{ LnLABOR } & $0.2696^{* * *}$ & $-0.8053^{* * *}$ & $0.2002^{* *}$ \\
& $(6.7130)$ & $(-6.7603)$ & $(2.5246)$ \\
\hline \multirow{2}{*}{ LnCAPITAL } & $0.3278^{* * *}$ & $0.6839^{* * *}$ & $0.6447^{* * * *}$ \\
& $(9.9780)$ & $(24.3361)$ & $(19.9092)$ \\
\hline \multirow{2}{*}{ LnIRA/LAND } & $0.5504^{* * *}$ & $0.3322^{* * *}$ & $0.5001^{* * * *}$ \\
& $(14.1479)$ & $(5.1357)$ & $(7.2760)$ \\
\hline LnFER & $0.4420^{* * *}$ & $0.2833^{* * *}$ & $0.5109^{* * * *}$ \\
& $(18.9839)$ & $(7.7808)$ & $(13.7329)$ \\
\hline R-Squared & 0.9158 & 0.9902 & 0.8333 \\
\hline AdjustedR-Squared & 0.9141 & 0.9889 & 0.8299 \\
\hline F-Statistic & $531.1656^{* * *}$ & $764.9899^{* * * *}$ & $244.0829 * * *$ \\
\hline Hausman Test & & \multicolumn{2}{c}{$200.5788^{* * * *}$} \\
\hline Notes: **** significant at $1 \%, * *$ significant at $5 \%$. &
\end{tabular}

Based on the results of the Hausman test, it is significant at the $1 \%$ level, and we can conclude that the fixed effect model is preferred for the case in Table 3. The results for case 2 above had the same impacts as in case 1 above.

Table 3. The Impact of Soil and Water Conservation on the Per Capita Disposable Income of Rural Households.

\begin{tabular}{|c|c|c|c|}
\hline IV & Pooled OLS & Fixed Effect & Random Effect \\
\hline Constant & $\begin{array}{l}6.1510 * * * \\
(20.3847)\end{array}$ & $\begin{array}{l}9.5435^{* * *} \\
(9.0574)\end{array}$ & $\begin{array}{c}3.4870 * * * \\
(9.4021)\end{array}$ \\
\hline LnSWCA & $\begin{array}{c}0.1622 * * * \\
(9.5599)\end{array}$ & $\begin{array}{c}0.0929 * * * \\
(4.7403)\end{array}$ & $\begin{array}{c}0.1214^{* * *} \\
(6.1523)\end{array}$ \\
\hline LnLAND & $\begin{array}{c}-0.3997^{* * *} \\
(-8.6137)\end{array}$ & $\begin{array}{c}-0.5191^{* * *} \\
(-4.0514)\end{array}$ & $\begin{array}{c}-0.3799^{* * *} \\
(-5.4351)\end{array}$ \\
\hline LnLABOR & $\begin{array}{c}-0.2184^{* * *} \\
(-5.4399)\end{array}$ & $\begin{array}{c}-0.9338^{* * *} \\
(-9.3400)\end{array}$ & $\begin{array}{c}-0.2424^{* * *} \\
(-3.5053)\end{array}$ \\
\hline LnCAPITAL & $\begin{array}{l}0.3305^{* * *} \\
(10.1548)\end{array}$ & $\begin{array}{l}0.7138 * * * \\
(26.4646)\end{array}$ & $\begin{array}{l}0.6787^{* * *} \\
(25.4246)\end{array}$ \\
\hline LnIRA/LAND & $\begin{array}{c}0.3008^{* * *} \\
(6.9731)\end{array}$ & $\begin{array}{c}0.2483^{* * *} \\
(3.8876)\end{array}$ & $\begin{array}{c}0.3625^{* * *} \\
(6.2666)\end{array}$ \\
\hline LnFER & $\begin{array}{l}0.3684^{* * *} \\
(16.1497)\end{array}$ & $\begin{array}{c}0.2856^{* * *} \\
(6.9306)\end{array}$ & $\begin{array}{l}0.3677^{* * *} \\
(17.6799)\end{array}$ \\
\hline R-Squared & 0.6834 & 0.9713 & 0.8698 \\
\hline AdjustedR-Squared & 0.6770 & 0.9674 & 0.8671 \\
\hline F-Statistic & $105.4315^{* * *}$ & $254.8993 * * *$ & $326.1018^{* * *}$ \\
\hline Hausman Test & & \multicolumn{2}{|c|}{$171.0427 * * *$} \\
\hline
\end{tabular}

Notes: *** significant at $1 \%$. 


\subsection{Discussion}

The increase in soil and water conservation has had a positive impact on rural incomes in China [24]. The places where more emphasis is placed on managing the environment will reap greater benefits. In relation to capital, in theory, the more capital that is invested, and the higher the output should be. This also applies to fertilizers and irrigation. They are both used to improve productivity and efficiency, and areas, where they are a more prominent show, increased agricultural output.

In contrast to other studies, the findings show that farmland area and the number of agricultural workers have negative impacts on agricultural economic growth and the per capita disposable income of rural households. The law of diminishing marginal utility may explain this. Under a certain level of production technology, when the input of other production factors is unchanged, with a continuous increase in the input of specific production factors, the increase in the total output will be smaller after it reaches a certain point. The marginal utility may decrease into negative utility, because it may be unfavourable to consume another unit of any investment. One explanation is that higher labour intensity may cause lower productivity and per capita income. This can be offset by technical improvements, investment in infrastructure and market access, or opportunities [28,29].

\section{Conclusions}

From the empirical findings, the macro level and micro level data shows:

(1) At the macro level:

The agricultural economy is the foundation of a country. Soil and water conservation can support sustainable agricultural development in China. Environmentally-friendly practices should be encouraged and used by the agricultural sector in China.

(2) At the micro level:

Poverty mainly occurs in rural areas, and soil and water conservation can have a significant effect on poverty reduction. More environmentally-friendly practices applied in the agricultural sector will lead to a higher output. A higher output usually leads to higher incomes for rural workers and reduces the problems caused by poverty in rural China.

To investigate the topic in further detail, farmland area, the number of agricultural workers, agricultural productive fixed assets, irrigation area, and the consumption of chemical fertilizer was added as control variables in the two models.

Capital input remains the most influential factor in agricultural poverty reduction. Irrigation area plays less of a role in increasing the per capita disposable income of rural households than agricultural GDP growth. The consumption of chemical fertilizer plays an important role in increasing agricultural GDP and per capita disposable income. Therefore, local areas should adopt the measures that are most suited to their specific environment and conditions.

Growth in agricultural GDP leads to a reduction in unemployment because of the increased opportunities in agriculture. This helps to reduce inflation rates and encourages more investment in rural economies.

In contrast to previous work, this study shows the effect of capital investment and soil and water conservation on the expansion of farmland area, agricultural worker growth, agricultural economic growth, and rural poverty reduction. This also indicates that, rather than just farmland area and agricultural labour, soil quality and capital input are also necessary to improve agricultural economic growth and per capita disposable income. This is determined by different socio-economic structures and natural resource endowments in different periods.

Throughout the history of agriculture, deforestation has been used to expand the area used for animal grazing or growing crops. The overexploitation of natural resources in agricultural production cannot be compensated for by the expansion of farmland area or by increasing the number of agricultural workers. Therefore, the decrease in agricultural economic growth and the per disposable 
capital income of rural households caused by agricultural land degradation cannot be improved in the short term through environmental measures.

The conclusions in this study provide important policy recommendations that the government can use to prioritize future projects on soil and water conservation. It could lead to many benefits if government resources are rationally allocated. Furthermore, soil and water conservation is also determined by the private decisions of people in rural households. Since they also play a central role in sustainable rural development, farmers should promote and participate in soil and water conservation practices.

To increase agricultural economic growth and the per capita disposable income of rural households, more importance should be given to land quality and capital investment. In the current environment, land quality and capital input are the keys to solving the vicious circle of "population growth, farmland expansion, land degradation, low productivity, and rural poverty".

\section{Policy Recommendations}

Based on the research results and the status of soil and water conservation, policy recommendations include:

(1) First, continue to increase investment in soil and water investment conservation, because it helps to promote agricultural economic growth and reduce poverty.

(2) Second, institutions for soil and water conservation should be established at the central and local levels. By undertaking key responsibilities in new rural projects, local governments can set expenditures and increase the budgets for rural soil and water investments. This will establish a steady growth mechanism in rural economies. Policies should be formulated to encourage the participation of the community in new rural projects and attract investment from banks and other sources to fund soil and water conservation. It is also necessary to establish a diversified rural construction investment mechanism in order to promote agricultural economic growth, increase non-agricultural employment, and alleviate poverty. This will improve stability, infrastructure, and prosperity in domestic economies.

(3) Third, with a labour force surplus in the agricultural sector, the government needs to devote more efforts to entire-village advancement, labour force transfer training, and industrial poverty relief. This will promote economic and social development in deprived areas and raise income levels and living standards. Training involves increasing the skill level of the labour force, which is crucial due to the advancement of technology.

(4) Fourth, the transition from labour-intensive agriculture to technology-intensive agriculture further should be advanced. Soil and water conservation allows denser vegetation and strengthens the soil structure, so it is less prone to erosion. Engineering and physiological measures are the primary methods that are used for soil and water conservation. Some appropriate techniques include minimum tillage, crop rotation, sub-soiling, and some mechanical measures, all of which rely on advanced technology. In order to eliminate barren land reclamation and maintain the productivity of existing farmland, farmers need the guidance and support of the government about soil and water conservation projects and related technologies. Face-to-face training courses can be provided for farmers to help them learn short and long-term conservation techniques.

(5) Finally, it is important to encourage the participation of multilevel stakeholders in further soil and water developments. Furthermore, soil quality and topography are also critical determinants of household welfare. The impact of soil and water conservation on household welfare demonstrates the link between poverty and the environment. Farmers should be eager to participate in the improvement of the environment. It is better to use soil and water conservation methods while farming, rather than control soil and water loss after the soil has decreased in quality. Non-governmental organizations (NGOs) should also play a role in soil and water conservation projects. Conservation not only aims to protect, but it also involves the improvement and 
rational use of land. Natural resources should be integrated into farming systems. Soil and water conservation and sustainable rural development are complex and in the early stages of development. In order for them to be effective, members of all of the relevant parts of society need to play their part.

\section{Suggestions for Future Study}

(1) This method can be applied to future studies to analyze the impact of soil and water conservation on agricultural economic growth and rural poverty reduction. It can be applied to different countries and compare different situations in developed and developing countries.

(2) Due to the limited time and missing data, the rural poverty reduction is represented by the per capita disposable income of rural households. In future studies, other dependent variables may be used such as the Engel coefficient, or the rate of poverty.

(3) The dummy variables, such as climate change, need to be studied further to improve the accuracy of the model.

Author Contributions: C.S. gathered the data, and estimated the model.; A.S.A.-R. presented the determinants of the agricultural economic growth and rural poverty reduction and put together all the numerical results; A.S.A.-R. contributed with conclusions and recommendations as well as with the limitations of the study and further research; A.W.N. conducted the literature review and amendment process; and C.S. was responsible for the overall writing process.

Funding: The Authors are thankful for the financial support under the Universiti Putra Malaysia (High Impact Journal Publication Fund).

Acknowledgments: Grateful thanks to the anonymous reviewers for the valuable comments that helped to improve the manuscript considerably.

Conflicts of Interest: The authors declare no conflict of interest.

\section{References}

1. David Pimentel. Soil erosion: A food and environmental threat. Environ. Dev. Sustain. 2006, 8, 119-137. [CrossRef]

2. Shi, X.Z.; Yu, D.S.; Yang, G.X.; Wang, H.J.; Sun, W.X.; Du, G.H.; Gong, Z.T. Cross-reference system for translating between genetic soil classification of China and soil taxonomy. Soil Sci. Soc. Am. J. 2006, 70, 78-83. [CrossRef]

3. Chinese Academy of Science and Ministry of Water Resources. Muddy China is facing more landslides. 2008. Available online: http:/ / english.iswc.cas.cn/ (accessed on 16 August 2017).

4. Cheng, J.G.; Yang, X.L.; Wei, C.J.; Zhao, W. On water safety. China Water Resour. 2004, 1, 21-23. (In Chinese) [CrossRef]

5. Zhang, X.; Shao, M.; Li, S.; Peng, K. A review of soil and water conservation in China. J. Geogr. Sci. 2004, 14, 259-274.

6. China's Ministry of Agriculture. China Agriculture Yearbook 2013 Contents. Available online: http: / / english.agri.gov.cn/service/ayb/201411/P020141104533729567763.pdf (accessed on 19 September 2016).

7. National Bureau of Statistics of China. 2009. Available online: http://data.stats.gov.cn/english/easyquery. htm?cn=C01 (accessed on 1 January 2017).

8. Chen, Y.P.; Liu, M.; Zhang, Q. Development of financial intermediation and the dynamics of urban-rural disparity in China, 1978-1998. Reg. Stud. 2010, 44, 1171-1187. [CrossRef]

9. Steffan, J.J.; Brevik, E.C.; Burgess, L.C.; Cerdà, A. The effect of soil on human health: An overview. Eur. J. Soil Sci. 2017. [CrossRef] [PubMed]

10. Zhang, X.; Yang, L.; Li, Y.; Li, H.; Wang, W.; Ye, B. Impacts of lead/zinc mining and smelting on the environment and human health in China. Environ. Monit. Assess. 2012. [CrossRef] [PubMed]

11. Cao, H.B.; Chen, J.J.; Zhang, J.; Zhang, H.; Qiao, L.; Men, Y. Heavy metals in rice and garden vegetables and their potential health risks to inhabitants in the vicinity of an industrial zone in Jiangsu, China. J. Environ. Sci. 2010, 22, 1792-1799. [CrossRef] 
12. Zheng, N.; Liu, J.; Wang, Q.; Liang, Z. Health risk assessment of heavy metal exposure to street dust in the zinc smelting district, northeast of China. Sci. Total Environ. 2010, 408, 726-733. [CrossRef] [PubMed]

13. Shi, J.C.; Yu, X.L.; Zhang, M.K.; Lu, S.G.; Wu, W.H.; Wu, J.J. Potential risks of copper, zinc, and cadmium pollution due to pig manure application in a soil-Rice system under intensive farming: A case study of Nanhu, China. J. Environ. Qual. 2011, 40, 1695-1704. [CrossRef] [PubMed]

14. Wang, X.L.; Sato, T.; Xing, B.S.; Tao, S. Health risks of heavy metals to the general public in Tianjin, China via consumption of vegetables and fish. Sci. Total Environ. 2005, 350, 28-37. [CrossRef] [PubMed]

15. Lai, H.Y.; Hseu, Z.Y.; Chen, T.C.; Chen, B.C.; Guo, H.Y.; Chen, Z.S. Health risk-based assessment and management of heavy metals-contaminated soil sites in Taiwan. Int. J. Environ. Res. Public Health 2010, 7, 3595-3614. [CrossRef] [PubMed]

16. John, G.F.; Andrew, B. A lead isotopic study of the human bioaccessibility of lead in urban soils from Glasgow, Scotland. Sci. Total Environ. 2011, 409, 4958-4965.

17. Yang, Q.; Rui, L.I. The Investment for Soil and Water Conservation and Its Impacts on Rural Economy in Northeast China. Bull. Soil Water Conserv. 2008, 28, 170-175. (In Chinese)

18. Reardon, T.; Vosti, S.A. Links between rural poverty and the environment in developing countries: Asset categories and investment poverty. World Dev. 1995, 23, 1495-1506. [CrossRef]

19. Futian, Q.; Nico, H.; Wan, M.W. Land administration reform in China: Its impact on land allocation and economic development. Land Use Policy 1995, 12, 193-203.

20. Li, X.; Wang, G.; Li, R. Relationship between soil erosion and poverty. Soil Water Conserv. Res. 2007, 14, 132-134, (In Chinese with English abstract).

21. David, P.; Michael, B. Soil erosion threatens food production. Agriculture 2013, 3, 443-463. [CrossRef]

22. Hu, S. Econometric Analysis of the Correlation between Soil erosion and Poverty. For. Econ. 2008, 28, 544-547.

23. Di, B.; Ning, D.; Lu, S. Analysis of the Relationship between Soil Erosion and Poverty in China. Bull. Soil Water Conserv. 2006, 26, 67-72. (In Chinese with English abstract)

24. Kuang, Y.; Luo, H. An Empirical Study on the Relationship between Soil and Water Conservation and Agricultural Economic Growth, Poverty Reduction. Agric. Econ. 2010, 1, 54-58.

25. Lu, J.; Chen, G. Impact of Soil Erosion on Rural Poverty. Asian Agric. Res. 2013, 5, 21.

26. Place, F.; Swallow, B.M.; Wangila, J.; Barrett, C.B. Lessons for natural resource management technology adoption and research. In Natural Resources Management in African Agriculture: Understanding and Improving Current Practices; Barrett, C.B., Place, F., Aboud, A.A., Eds.; Commonwealth Agricultural Bureau International: Wallingford, UK, 2002.

27. Feng, D.; Chen, W.; Chu, X. Study of Comprehensive Evaluation of Poverty Reduction Effect for Chinese Poverty-Stricken Areas-Based on the Data of Chinese 14 Contiguous Poor Areas. Appl. Econ. Financ. 2016, 3, 37-44. [CrossRef]

28. Binswanger, H.P.; McIntire, J. Behavioral and material determinants of production relations in land-abundant tropical agriculture. Econ. Dev. Cult. Chang. 1987, 36, 73-99. [CrossRef]

29. Pender, J.; Jagger, P.; Nkonya, E.; Sserunkuuma, D. Development pathways and land management in Uganda: Causes and implications. World Dev. 2004, 32, 5767-5792. [CrossRef] 